\title{
TOMOGRAFIA COMPUTADORIZADA NA ANÁLISE DOS PADRÕES DE CALCIFICAÇ̃̃ES NOS TUMORES ÓSSEOS DA BACIA EM PEDIATRIA: NOVA ABORDAGEM*
}

\author{
Gabriel Antônio de Oliveira', Henrique Zambenedetti Werlang ${ }^{2}$, Pedro Martins Bergoli², \\ Madalena Frechiani ${ }^{3}$, Fernão Oliveira ${ }^{4}$
}

Resumo OBJETIVO: No grupo pediátrico, o diagnóstico radiológico dos tumores dos ossos ilíacos, ísquios e púbis apresenta dificuldades e peculiaridades próprias, mas a literatura revisada não trata especificamente desse tema. Este trabalho pretende investigar a existência de padrões radiológicos confiáveis para o diagnóstico diferencial desses tumores. MATERIAIS E MÉTODOS: Foram revistos os achados radiológicos de tumores dos ossos do quadril em dez pacientes com idades entre 8 e 19 anos. RESULTADOS: Reação óssea (esclerose ou lise), reação periosteal (lamelar em camada única, múltiplas camadas ou radial), extensão do tumor no osso e grau de invasão das partes moles revelaram baixa especificidade. As calcificações nas partes moles, consideradas em conjunto, foram inespecíficas. Contudo, separando as próximas do osso comprometido, que apresentam formas e tamanhos variados - padrão I - , daquelas afastadas do osso, finas e amorfas padrão II - observamos que o padrão I foi totalmente inespecífico e o padrão II foi identificado nos três casos de osteossarcoma (100\%) e em apenas um dos casos de Ewing (16,6\%). CONCLUSÃo: Neste material, as calcificações padrão II revelaram sensibilidade de $100 \%$ e especificidade de $90 \%$ para osteossarcoma. Contudo, sua importância pode não se limitar ao diagnóstico radiológico. As calcificações padrão II indicam, provavelmente, os sítios ideais para biópsia.

Unitermos: Tumores ósseos; llíaco; Quadril; Pediatria; Tomografia computadorizada.

Abstract Computed tomography in the analysis of calcification patterns in pediatric bone tumors of the hip: a new approach.

OBJECTIVE: In the pediatric group, the radiological diagnosis of bone tumors of the hip is difficult and presents some peculiarities, but reviewed literature does not approach this specific problem. The objective of the present study was to investigate the existence of reliable radiological patterns for the differential diagnosis of these tumors. MATERIALS AND METHODS: Radiological findings of bone tumors of the hip in ten patients in the age range between 8 and 19 years have been reviewed. RESULTS: Bone reaction (sclerosis or lysis), periosteal reaction (lamellar with single or multiple layers, or radial), tumor extent in the bone and level of soft tissues invasion have presented low specificity. Soft tissue calcifications, when considered as a whole, were non-specific. However, when those calcifications with varied shapes and sizes, nearby the affected bone (pattern I) were separated from those, thin and amorphous, away from the bone (pattern II), we have observed that the pattern I was totally non-specific, and the pattern II was found in the three cases of osteosarcoma $(100 \%)$ and in only one case of Ewing's sarcoma (16.6\%). CONCLUSION: In the present study, pattern II calcifications have shown a $100 \%$ sensitivity and $90 \%$ specificity for osteosarcoma. However, their importance may be not limited to the radiological diagnosis. Pattern II calcifications indicate probably ideal sites for biopsy.

Keywords: Bone tumors; Ilium; Hip; Pelvis; Pediatrics; Computed tomography.

* Trabalho realizado no Serviço de Diagnóstico por Imagem do Hospital Infantil Nossa Senhora da Glória, Vitória, ES.

1. Médico Radiologista do Hospital Infantil Nossa Senhora da Glória, Preceptor de Radiologia Pediátrica da Residência Médica do Centro de Diagnóstico por Imagem/Hospital Universitário Cassiano Antônio de Morais/Hospital Infantil Nossa Senhora da Glória.

2. Médicos Radiologistas, ex-Residentes do Centro de Diagnóstico por Imagem/Hospital Universitário Cassiano Antônio de Morais/Hospital Infantil Nossa Senhora da Glória.

3. Médica Oncologista Pediátrica do Hospital Infantil Nossa Senhora da Glória.

4. Médico Radiologista do Hospital Infantil Nossa Senhora da Glória.

Endereço para correspondência: Dr. Gabriel de Oliveira. Rua Sagrado Coração de Maria, 220, Praia do Canto. Vitória, ES, 29055-770. E-mail: hzwerlang@gmail.com

Recebido para publicação em 8/9/2005. Aceito, após revisão, em 29/3/2006

\section{INTRODUÇÃO}

Nos ossos longos, radiografias simples em incidências ortogonais são muito úteis na formulação de hipóteses diagnósticas. As diferentes lesões tendem a apresentar maior incidência nas epífises, metáfises ou diáfises ${ }^{(1)}$. Os osteossarcomas, por exemplo, costumam ser metafisários; os tumores de Ewing, diafisários ou metadiafisários. Nos ossos do quadril (ilíaco, ísquio e púbis), ao contrário, incidências ortogonais não são possíveis e as lesões não podem ser agrupadas segundo sua disposição longitudinal. Além disso, a superposição de imagens das vísceras pélvicas e dos seus conteúdos dificulta a análise das radiografias simples, tornando a tomografia computadorizada (TC) essencial para o diagnóstico. A manutenção da hematopoiese é outra característica dos ossos do quadril — nos ossos longos, ocorre substituição da medula óssea vermelha pela amarela. Essas particularidades fazem com que os tumores do ilíaco apresentem alguns aspectos radiológicos distintos dos demais ossos. 
Na literatura revisada, não foram encontrados, no grupo pediátrico, artigos abordando especificamente a semiologia radiológica nos tumores dos ossos do quadril.

\section{MATERIAIS E MÉTODOS}

Foram analisados, retrospectivamente, os prontuários de dez pacientes com tumores dos ossos do quadril, confirmados histologicamente e documentados através de radiografias simples e/ou TC. As tomografias foram analisadas na fase sem contraste intravenoso, evitando confundir vasos tumorais com calcificações. A ressonância magnética $(\mathrm{RM})$, pouco adequada para o diagnóstico, não foi apresentada neste trabalho, embora tenha papel fundamental no estadiamento dessas lesões. As imagens obtidas pós-tratamento químio e/ou radioterápico não foram utilizadas, assim como as obtidas após a administração intravenosa do meio de contraste. No primeiro caso, porque houve importante aumento das calcificações nas partes moles tumorais, provavelmente decorrendo de necrose tissular. No segundo, porque o realce tissular e neovascular poderia ser confundido com as calcificações no tumor.

Por apresentarem características próprias e outras comuns as demais vértebras, o sacro e o cóccix, apesar de participantes da estrutura óssea da bacia, foram excluídos deste trabalho.

A casuística foi limitada às duas primeiras décadas da vida por serem diversas as afecções que comprometem esses ossos nos demais grupos etários. Seis casos tiveram diagnóstico histológico de Ewing, em três o diagnóstico foi de osteossarcoma e em um, de condrossarcoma. As idades variaram de 8 a 19 anos. Seis pacientes eram do sexo masculino e quatro eram do sexo feminino.

Os demais critérios empregados na análise encontram-se na Tabela 1.

\section{RESULTADOS}

Em todos os pacientes o sintoma inicial foi dor, referida restrita ao quadril em sete, no quadril com irradiação para a coxa em um e na coxa e/ou joelho em dois. Todos os pacientes apresentaram massa palpável ao diagnóstico.
Tabela 1 Critérios empregados na avaliação dos tumores.

\begin{tabular}{|c|c|}
\hline Apresentação clínica & \\
\hline Ossos afetados & Ilíaco; ísquio; púbis \\
\hline Tamanho da lesão óssea* & $<25 \% ; 25-50 \% ;>50 \%$ \\
\hline Reação óssea predominante & $\begin{array}{l}\text { Lítica; esclerótica; mista (lítica e esclerótica em proporções } \\
\text { equivalentes) }\end{array}$ \\
\hline Comprometimento da cortical & Ausente; presente \\
\hline Tipo de reação periosteal & $\begin{array}{l}\text { Radial; lamelar em camada única; lamelar em múltiplas ca- } \\
\text { madas }\end{array}$ \\
\hline Massa tumoral extra-óssea $^{\dagger}$ & Ausente; presente \\
\hline Calcificações padrão I & Ausentes; presentes \\
\hline Calcificações padrão $\|^{\S}$ & Ausentes; presentes \\
\hline Calcificações padrão III $^{\text {T }}$ & Ausentes; presentes \\
\hline Invasão óssea por contigüidade** & Ausente; presente \\
\hline Metástases ao diagnóstico & Ausentes; presentes \\
\hline
\end{tabular}

* Considerada em relação ao percentual do osso acometido. Se mais de um osso (ilíaco, ísquio ou púbis) for comprometido, considerar-se-á o tamanho da lesão no maior osso.

${ }^{\dagger}$ Considerada em relação à maior espessura do osso acometido.

‡ Quando de tamanhos e formas diversas, localizadas a uma distância igual ou inferior à medida da maior espessura do osso normal contralateral, no mesmo plano de corte (caso 3, figura C).

$\S$ Quando finas e amorfas, localizadas a uma distância superior à medida da maior espessura do osso normal contralateral, no mesmo plano de corte.

"Quando arredondadas, definidas, habitualmente encontradas em matriz condróide calcificada.

** Na ausência de cartilagem separando o ilíaco, ísquio e púbis, o comprometimento de mais de um desses ossos não será considerada invasão por contigüidade.
A lesão envolveu menos de $25 \%$ do osso em dois casos de Ewing e em um de condrossarcoma, entre $25 \%$ e $50 \%$ em um caso de Ewing e em um osteossarcoma, e mais de 50\% em três casos de Ewing e em dois osteossarcomas.

Os três casos de osteossarcomas tiveram lesões ósseas predominantemente escleróticas ( $\operatorname{casos} 7,8$ e 9). Nos casos de tumor de Ewing, houve predomínio de lesões escleróticas em três (casos 1, 4 e 6), líticas em dois (casos 2 e 5) e equilíbrio entre esclerose e lise em um (caso 3). No condrossarcoma, houve lesão lítica (caso 10). As lesões apresentaram padrão permeativo em todos os casos, com limites mal definidos entre as áreas normais e as comprometidas.

A cortical estava comprometida em todos os casos.

A reação periosteal radial ocorreu nos três osteossarcomas, num deles associada à reação lamelar em camada única (caso 9).

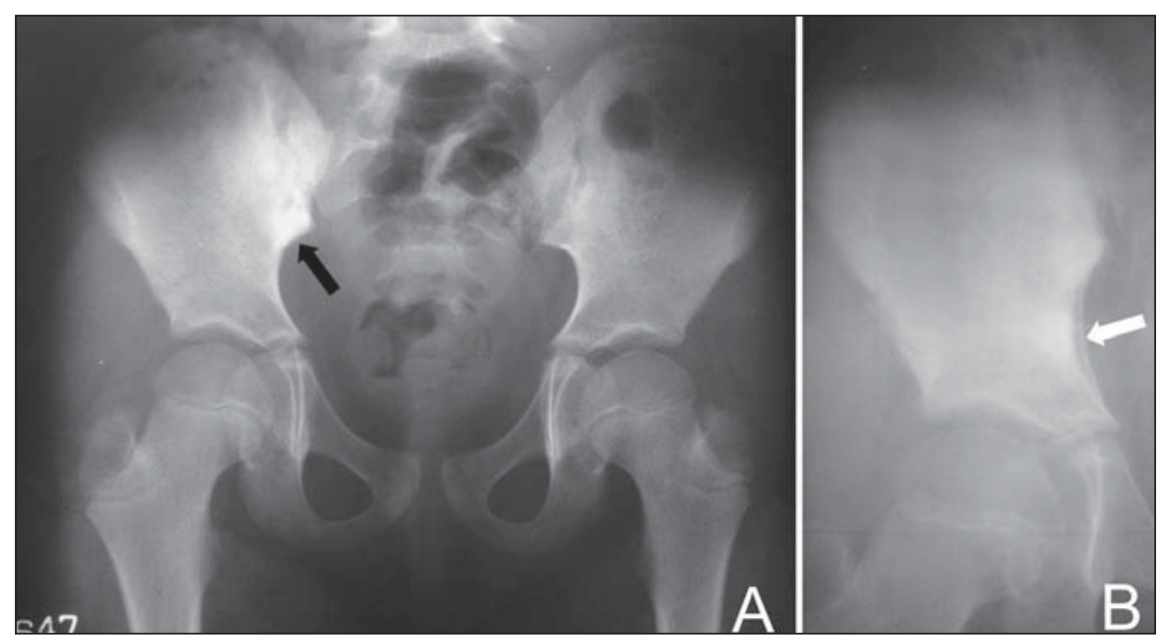

Figura 1. Caso 1. Tumor de Ewing. Menina de oito anos de idade. A: Pequena área esclerótica no ilíaco, próxima ao terço distal da articulação sacroilíaca (seta). B: Quatro meses após, a lesão óssea aumentou de tamanho e apareceu reação periosteal em camada única (seta); nesta ocasião havia massa palpável. 
Nos tumores de Ewing, dois não apresentaram nenhuma reação periosteal, dois apresentaram reação lamelar em camada única (casos 1 e 2), e dois, reação mista (casos 3 e 6). No caso do condrossarcoma a reação foi lamelar.

Massa tumoral extra-óssea foi demonstrada nos oito casos em que a TC e/ou RM estavam disponíveis, ocorrendo sempre a partir das duas faces e ultrapassando o maior eixo transverso do osso.

As calcificações em partes moles foram avaliadas sempre que a TC estava disponível para análise; as com padrão I foram encontradas em todos os casos (tumor de Ewing, osteossarcoma, condrossarcoma); as com padrão II foram encontradas nos casos de osteossarcoma e em um tumor de Ewing (caso 6). A maioria das calcificações

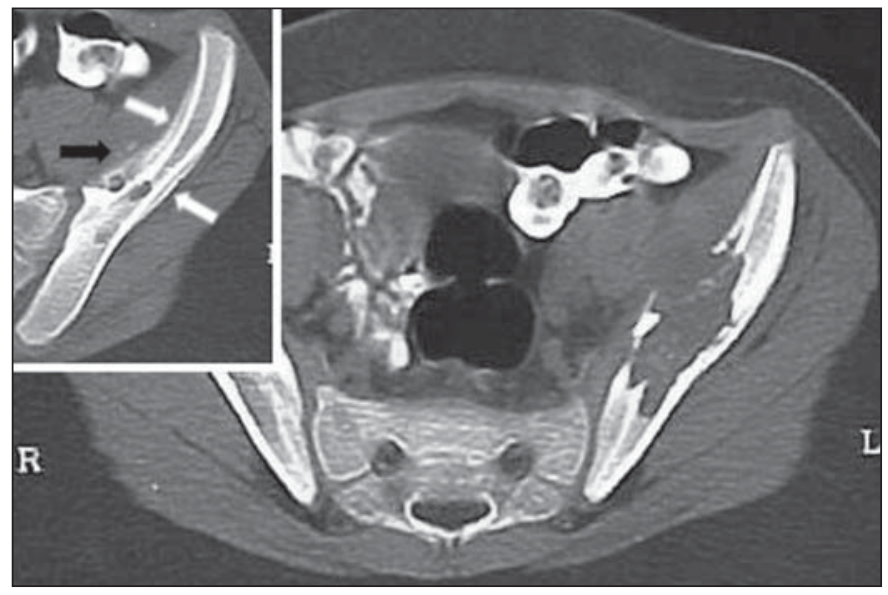

Figura 2. Caso 2. Tumor de Ewing. Menino de dez anos de idade. Lesão no ilíaco esquerdo, predominantemente lítica. No detalhe observam-se reação periosteal lamelar em camada única (setas brancas) e calcificações grosseiras, próximas ao osso (seta preta).
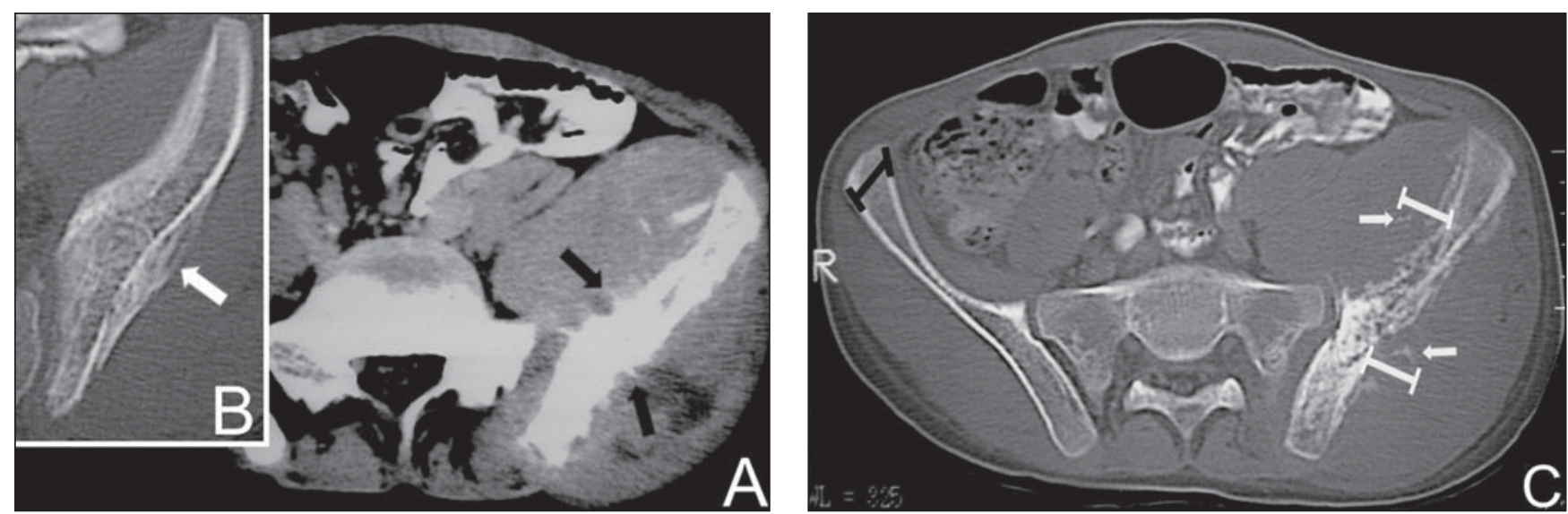

Figura 3. Caso 3. Tumor de Ewing. Menino de 13 anos de idade. A: Lesão permeativa de padrão misto (esclerose e lise) no ilíaco esquerdo, acompanhada de reação periosteal radial (setas); algumas calcificações grosseiras talvez representem fragmentos ósseos. B: Reação periosteal lamelar, em múltiplas camadas (seta). C: Outro corte do mesmo exame demonstrando que as calcificações nas partes moles estão a uma distância menor do que o maior diâmetro do osso contralateral, tomado como referência.

Figura 4. Caso 4. Tumor de Ewing. Menina de 14 anos de idade. Lesão predominantemente esclerótica no ilíaco esquerdo; no detalhe observa-se ruptura da cortical.

Figura 5. Caso 5. Tumor de Ewing. Menino de 16 anos de idade. Lesão predominantemente lítica do púbis direito.

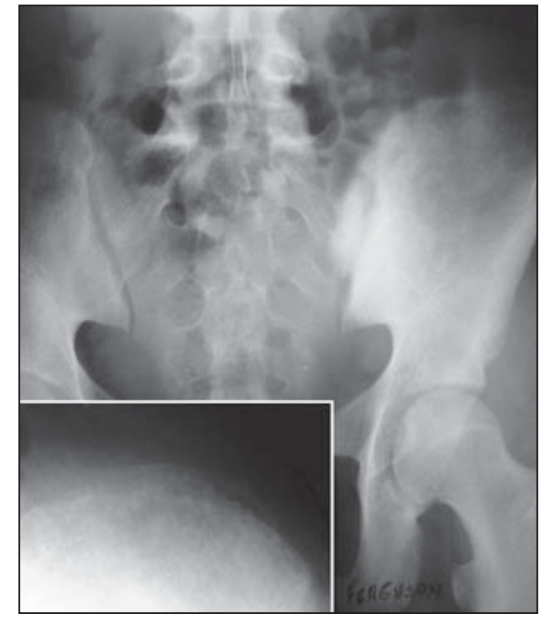

Figura 4

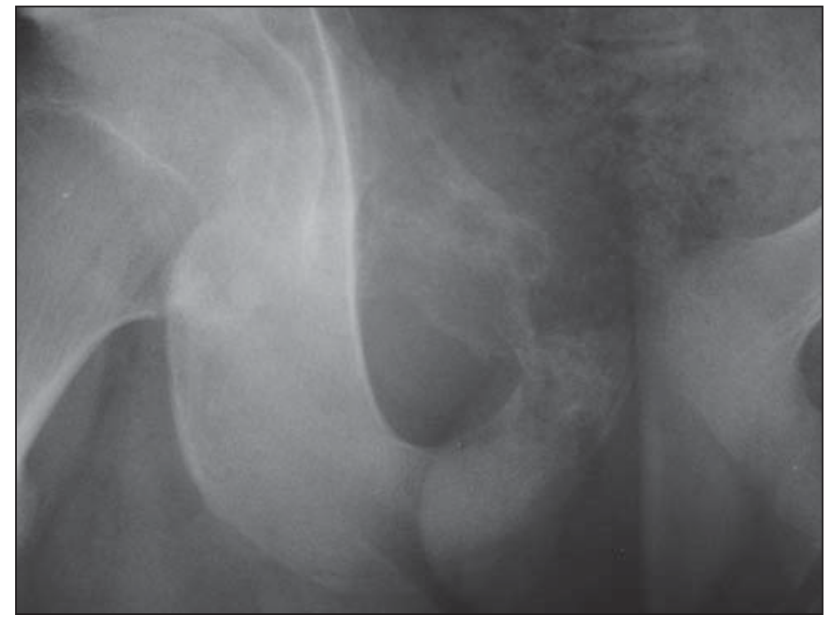

Figura 5 

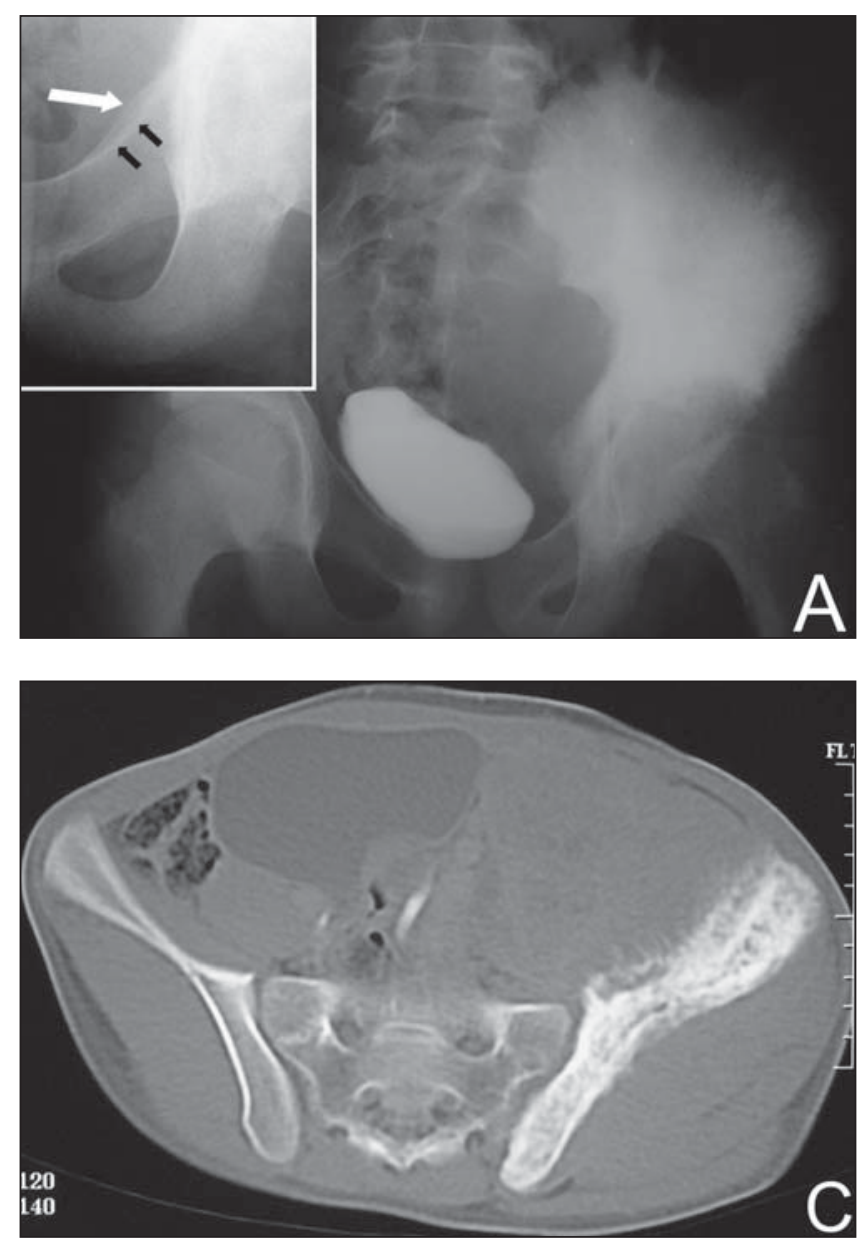

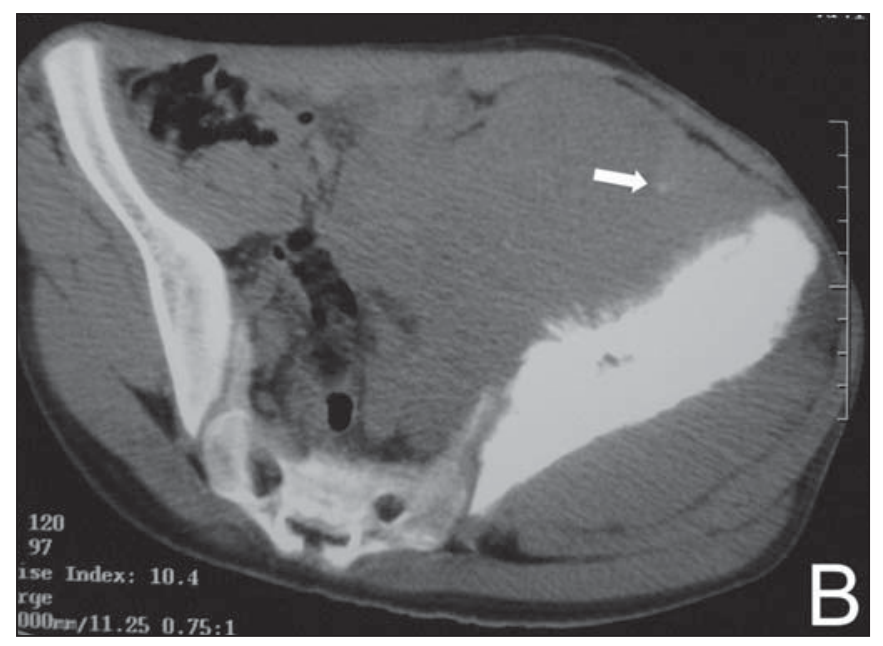

Figura 6. Caso 6. Tumor de Ewing. Menino de 12 anos de idade. A: RX evidenciando extensa esclerose no ilíaco esquerdo, associada a massa de partes moles que desloca a bexiga. 0 detalhe mostra reação lamelar em múltiplas camadas. B: TC sem contraste mostrando importante extensão tumoral extraóssea e pequeno foco de calcificação amorfo (seta). C: TC com contraste e janela óssea demonstrando reação periosteal, com componentes radial e lamelar. Observa-se aumento do diâmetro do osso, por aposição periosteal. (Caso cedido pelo Dr. Mário Flores, do Instituto da Criança do Hospital das Clínicas da Universidade de São Paulo).
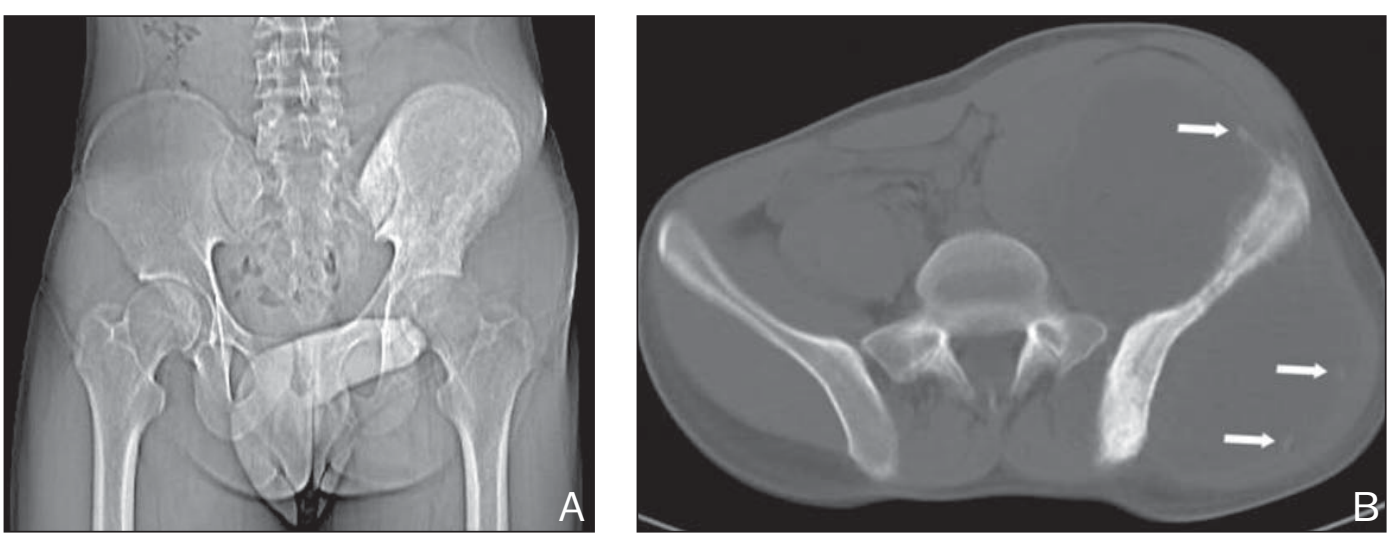

Figura 7. Caso 7. Osteossarcoma. Menino de 18 anos de idade. A: Topograma mostrando esclerose comprometendo todo o ilíaco esquerdo. B: A TC evidencia, além da lesão esclerótica do osso, tênues calcificações amorfas, afastadas do ilíaco (setas). (Caso cedido pelo Dr. Reinaldo B. Salgado, do Hospital São Lucas, Vitória, ES). próximas ao osso era de padrão I; todas as afastadas eram de padrão II. As com padrão III não foram encontradas.

Houve invasão por contigüidade para o sacro em apenas um caso de osteossarcoma, primitivo do ilíaco (caso 8).

Metástases ao diagnóstico foram encontradas em apenas um caso de tumor de Ewing (caso 6, metástases pulmonares).

\section{DISCUSSÃO}

Comprometimento do ilíaco ocorre em $18 \%$ dos tumores de Ewing e em $12 \%$ dos osteossarcomas. Os condrossarcomas comprometem mais este osso $(60 \%)$, mas são raros na infância e adolescência ${ }^{(2)}$. Por isso, a casuística apresentada neste trabalho pode ser considerada representativa.
Em sete pacientes houve grande comprometimento ósseo pelo tumor; o atraso no diagnóstico deve ter sido o maior responsável. Pequenas alterações na primeira radiografia da bacia foram negligenciadas no caso 1 . No caso 6, a dor era referida no joelho e a investigação inicial por imagem - que incluiu um exame de RM — limitou-se a este local. Apesar de ser um fato 

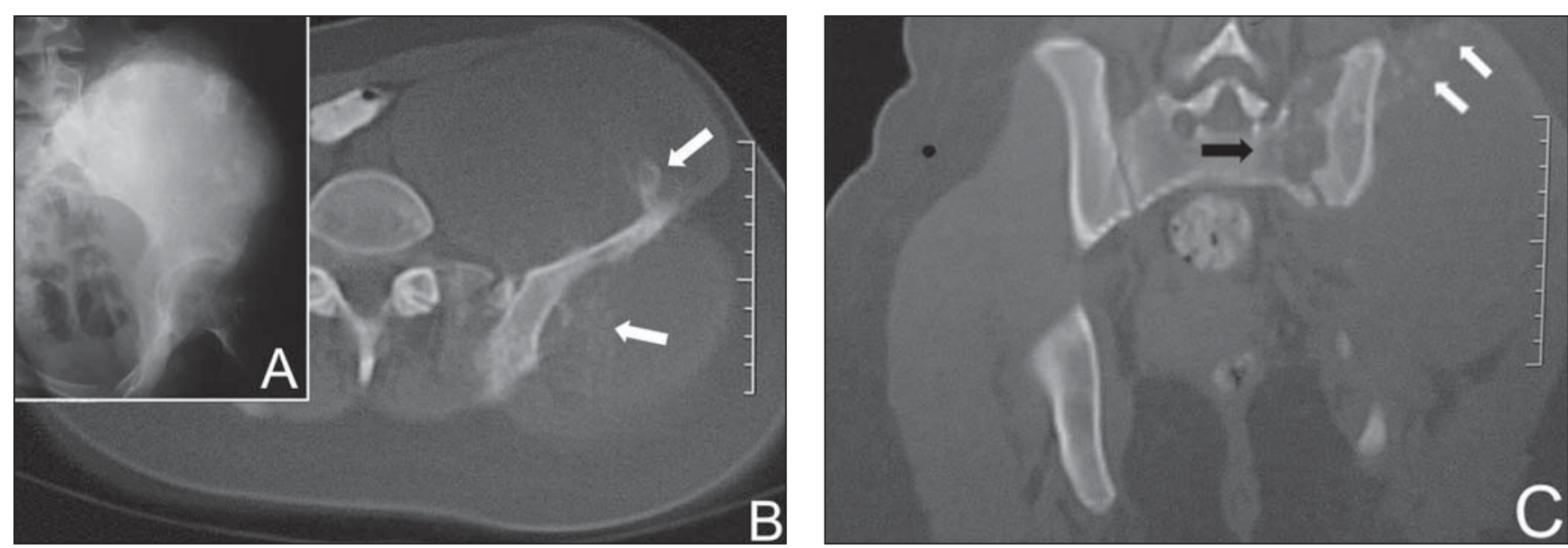

Figura 8. Caso 8. Osteossarcoma. Menina de 19 anos de idade. A: Radiografia evidenciando esclerose em todo o ilíaco esquerdo e tênues calcificações nas partes moles, adjacentes à crista ilíaca. B,C: TC mostrando tênues calcificações amorfas, algumas afastadas do osso (setas brancas), e lesão lítica na asa esquerda do sacro caracterizando invasão (seta preta).

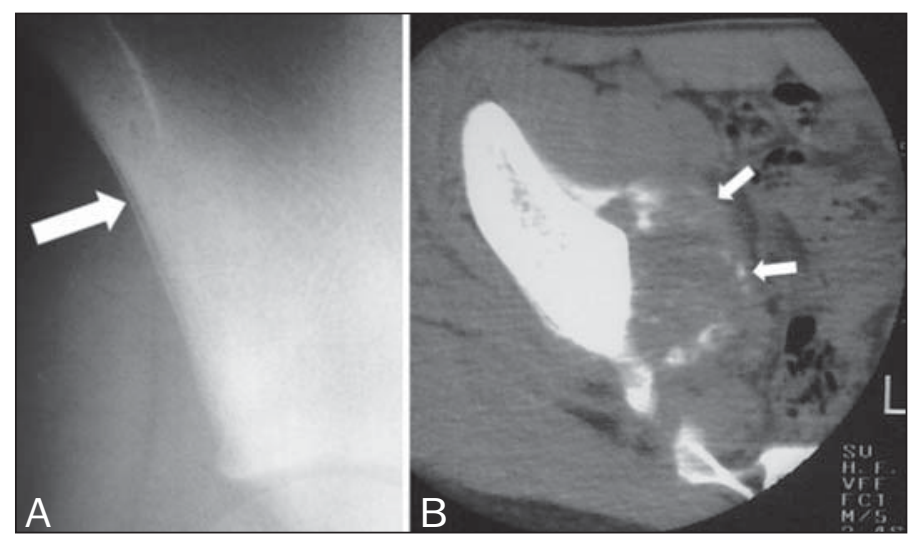

Figura 9. Caso 9. Osteossarcoma. Menino de 14 anos de idade. A: Radiografia evidenciando esclerose e reação periosteal lamelar em camada única no ilíaco direito (seta). B: TC mostrando calcificações amorfas, ditas "em nuvem", algumas muito afastadas do osso (setas).

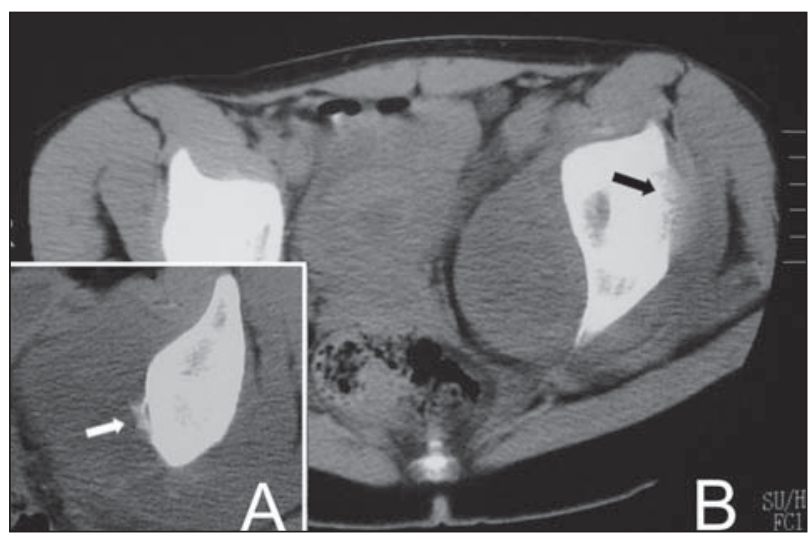

Figura 10. Caso 10. Condrossarcoma. Menina de 13 anos. de idade. A: Reação periosteal lamelar em camada única (seta). B: Ruptura da cortical (seta) e extensão extra-óssea. sobejamente conhecido, nunca é demais lembrar que a dor referida na coxa e/ou joelho pode estar relacionada com lesão óssea no quadril. Assim, sendo normais as radiografias da coxa ou joelho, a necessidade de estender a investigação radiológica à bacia sempre deve ser considerada.

Pode-se especular outros fatores para a existência de lesões tão extensas. No íliaco, ísquio e púbis, ao contrário dos ossos longos, inexistem as barreiras constituídas pelas cartilagens de conjugação e pela gordura - hipovascularizada — da medula óssea amarela. Isto facilitaria a disseminação de células tumorais.

Reações periosteal radiada e lamelar ocorreram em todos os tipos de tumores, embora a primeira tenha predominado nos osteossarcomas. Comprometimento da cortical e massa tumoral extra-óssea estiveram presentes em todos os casos.

As células tumorais têm a capacidade de estimular os osteoblastos a produzir esclerose, e os osteoclastos, lise. Lesões mistas ocorrem quando estas duas funções coexistem. Nos sarcomas osteogênicos, além desse estímulo, as células tumorais também produzem matriz osteóide (substância intercelular produzida por osteoblastos, normais ou tumorais). Esta matriz só é detectada pela imagem quando mineralizada ${ }^{(\mathbf{1})}$. Considere-se também que a quantidade de osteóide produzida pelos osteossarcomas depende da diferenciação predominante das células tumorais: osteoblástica, condroblástica ou fibroblástica. Porém, é impos- sível distinguir a esclerose reacional daquela resultante da produção de matriz osteóide pelos osteoblastos tumorais.

Predomínio de esclerose ocorreu em todos os casos de osteossarcoma, mas também em metade dos casos de Ewing. Predominância de osteólise só ocorreu no Ewing, mas pode ocorrer também em osteossarcomas, principalmente nos telangiectásicos, e na osteomielite.

No que se refere às calcificações nas partes moles, elas podem ocorrer em áreas de necrose tissular, metaplasia óssea induzida pelo tumor, fragmentos ósseos levados pelo tumor, reação periosteal ou resultar de depósito de cálcio na matriz tumoral (osteóide ou condróide). Essas calcificações apresentaram padrões distintos, conforme 
classificação na Tabela 1. As calcificações com padrão I foram totalmente inespecíficas. Isto ocorreu, provavelmente, pela impossibilidade de distinguir as decorrentes da calcificação da matriz osteóide (nos osteossarcomas) daquelas resultantes da reação periosteal e de fragmentos ósseos deslocados. As com padrão II foram evidenciadas em todos os sarcomas osteogênicos e em um dos Ewing (caso 6). Nos osteossarcomas, presumivelmente, resultaram da calcificação da matriz osteóide tumoral (ossificação). Como tumores de Ewing não produzem matriz osteóide, quando presentes, essas calcificações poderiam resultar da necrose, ou, eventualmente, de metaplasia óssea induzida pelo tumor ${ }^{(3)}$. Resnick diz que $9 \%$ dos tumores de Ewing calcificamse, porém não especifica quais os ossos acometidos, tampouco os tipos de calcificações. O mesmo autor mostra dois casos de tumor de Ewing do ilíaco com calcificações nas partes moles. Nesta situação, um diagnóstico radiológico errôneo de osteossarcoma pode ser induzido ${ }^{(4)}$.

Apesar dos avanços recentes da histopatologia, imuno-histoquímica, citogenética e microscopia eletrônica, o diagnóstico dos tumores de Ewing permanece um desafio, havendo dificuldade em diferenciálos de outros tumores, principalmente osteossarcomas de pequenas células ${ }^{(\mathbf{1 , 3 , 5}-\mathbf{1 5})}$, tumores da linhagem neuroectodérmica, principalmente os primitivos, e linfo- $\operatorname{mas}^{(\mathbf{1}, 4)}$. É sabido que tumores ósseos podem apresentar aspectos histológicos diversos, dependendo da área biopsiada. Na TC, áreas com calcificações padrão II sugerem a presença de matriz osteóide. Num tumor, sendo remota a possibilidade de metaplasia óssea induzida, a presença de matriz osteóide é geralmente considerada indicativa de osteossarcoma. Contudo, a possibilidade de que essas calcificações decorram de necrose tissular não pode ser desconsiderada.

Assim, se as biópsias não atingirem locais com as calcificações padrão II, existe a possibilidade de tecido osteóide — só aí existente - não ser incluído na lâmina. Nesta situação, um erro diagnóstico estaria ocorrendo. Biópsias guiadas por TC, visando a áreas com calcificações padrão II, poderiam evitar este erro.

Em suma, nos tumores do ilíaco, as calcificações nas partes moles parecem importantes para o diagnóstico radiológico presuntivo e, mais ainda, para orientar biópsias. Um protocolo específico com essa abordagem poderia ser aplicado em estudos prospectivos, preferencialmente multicêntricos.

\section{REFERÊNCIAS}

1. Baunin C, Rubie H, Sales de Gauzy J. Sarcoma d'Ewing. Ecycl Méd Chir Radiodiagnostic Appareil Locomoteur 2001;31:520-A-50,9p.

2. Schajowicz F. Neoplasias ósseas e lesões pseudotumorais. $2^{\underline{a}}$ ed. Rio de Janeiro: Revinter, 2000.
3. Schajowicz F. Current trends in the diagnosis and treatment of malignant bone tumors. Clin Orthop Relat Res 1983;180:220-252.

4. Resnick D. Tumor and tumor like lesions of bone: image and pathology of specific lesions. In: Resnick D, editor. Diagnosis of bone and joint disorders. 4th ed. Philadelphia: WB Saunders, 2002; 3763-4128.

5. Sim FH, Unni KK, Beabout JW, et al. Osteosarcoma with small cell simulating Ewing's tumors. J Bone Joint Surg [Am] 1979;61:207-215.

6. Martin SE, Dwyer A, Kissane JM, et al. Smallcell osteosarcoma. Cancer 1982;50:990-996.

7. Roessner A, Immenkamp M, Hiddemann W, et al. Case report 331. Small cell osteosarcoma of the tibia with diffuse metastatic disease. Skeletal Radiol 1985;14:216-225.

8. Edeiken J, Raymond AK, Ayala AG, et al. Smallcell osteosarcoma. Skeletal Radiol 1987;16:621628.

9. Ayala AG, Ro JY, Raymond AK, et al. A clinicopathologic study of 27 cases. Cancer 1989;64: 2162-2173.

10. Kyriakos M, Gilula LA, Becich MJ, et al. Intracortical small cell osteosarcoma. Clin Orthop 1992;279:269-280.

11. Sanjay B, Raj GA, Vishwakarma G. A small cell osteosarcoma with multiple skeletal metastasis. Arch Orthop Trauma Surg 1988;107:58-60.

12. Ayala AG, Ro JY, Papadopoulos NK, et al. Small cell osteosarcoma. Cancer Treat Res 1993;62: 139-149.

13. Mawad JK, MacKay B, Raymond AK, et al. Electron microscopy in the diagnosis of small round cell tumors of bone. Ultrastruc Pathol 1994;18: 263-268.

14. Nakajima H, Sim FH, Bond JR, et al. Small cell osteosarcoma of bone: review of 72 cases. Cancer 1997;79:2095-2106

15. Mulligan ME, Lewis DR Jr, Resnick CS, et al. Small cell osteosarcoma of the ulna: a case report and review of the literature. J Hand Surg [Am] 1999;24:417-420. 